\title{
SEMBLANZA
}




\section{De la gramática del texto al análisis crítico del discurso \\ Autobiografía académica y notas biobibliográficas \\ TEUN A. VAN DIJK}

\section{Edición: Alejandro Castro Barón ${ }^{86}$}

\section{Currículo de Teun A. van Dijk}

Teun Adrianus van Dijk (1943) se graduó en Lengua y Literatura francesa en la Universidad Libre de Ámsterdam y en Teoría Literaria en la Universidad de Ámsterdam, y obtuvo un doctorado en Lingüística de esta misma universidad, de la cual es profesor del Programa de Estudios del Discurso. Estudió también en Estrasburgo, París y Berkeley.

Ha recibido dos doctorados honoríficos, otorgados por las universidades de Buenos Aires y de Tucumán, y sus investigaciones han sido traducidas a una docena de idiomas (incluidos el ruso, el árabe, el chino y el japonés) y publicadas en más de 30 monografías y libros, y en alrededor de 300 artículos para revistas. Así mismo, ha sido conferencista en Europa y América, entre otros lugares.

En su primer trabajo investigativo abordó el estudio lingüístico de la literatura, pero pronto cambió al desarrollo de las "gramáticas textuales" y de la pragmática del discurso, seguido más tarde por los estudios (en parte con Walter Kintsch) sobre la psicología cognitiva del procesamiento del discurso.

Su trabajo durante los años ochenta se especializó en dos áreas. Por un lado, en el estudio de las estructuras, la producción y la comprensión de reportajes noticiosos y de prensa, y, por otro, en el análisis de la expresión del prejuicio étnico en varios tipos de discurso (como libros de texto, reportajes de noticias, conversaciones, discursos parlamentarios y discursos corporativos), con énfasis en las relaciones entre las estructuras del discurso con prejuicio, en las cogniciones sociales acerca de las minorías étnicas y la "gente del Tercer Mundo", y en las formas de reproducción del "racismo de élite" en las sociedades occidentales.

Este proyecto se ha extendido durante la última década hacia un estudio más general del papel del poder y de la ideología en el discurso y en la reproducción de las creencias sociopolíticas en la sociedad.

Teun A. van Dijk fundó la publicación holandesa Ttt (Taal, Tekst, Teken: Lenguaje, Texto, Signo) y cuatro revistas internacionales: Poetics, Text, Discourse and Society y, más recientemente, Discourse Studies, de las cuales continúa editando las dos últimas.

Desde 1999, Teun A. van Dijk trabaja en el Institut Univesitari de Lingüística Aplicada (IULA), de la Unviersitat Poempeu Fabra, Barcelona.

\footnotetext{
${ }^{86}$ Licenciado en Ciencias de la educación, editor de textos de lenguaje en Editorial Voluntad S.A. E-mail: alejandrocastrobaron@yahoo.com.
} 


\section{De la gramática del texto al análisis crítico del discurso}

\section{Autobiografía académica y notas biobibliográficas}

En este artículo $^{87}$ me gustaría esquematizar el desarrollo del trabajo que he realizado desde la "Gramática del Texto", a principios de la década de los 70 , hasta mis estudios actuales en Análisis Crítico del Discurso [ACD].

Esto parece especialmente útil debido a que la mayoría de mi trabajo traducido al español permanece aún en la primera fase de desarrollo académico, en lo gramatical del texto, mientras que apenas se conoce el trabajo posterior sobre Discurso y Racismo y sobre Análisis Crítico del Discurso ${ }^{88}$.

\section{Gramática del texto}

Para entender el interés que he tenido por las gramáticas del texto, es preciso recordar que mi primer amor académico fue la Teoría Literaria. Después de graduarme en Lengua y Literatura francesa (con especial interés en poesía surrealista), estudié Teoría Literaria. Me centré en el lenguaje literario y quise saber si la literatura podía ser caracterizada específicamente por su uso típico del lenguaje.

Bajo la influencia de la Gramática Generativa Transformacional [GGT] de Chomsky ${ }^{89}$, tal cuestión se verbalizó a finales de los 60 en términos de un conjunto especial de reglas que "generarían" (es decir, describirían estructuralmente) los textos literarios.

Sin embargo, la GGT nunca fue desarrollada para explicar las estructuras de los textos, y por lo tanto el objetivo de generar una "Poética Generativa" fue rápidamente reemplazado por el objetivo más importante a focalizar: una Gramática Generativa del Texto.

La razón de ser de tales gramáticas del texto era proveer una descripción explícita de las estructuras (gramaticales) de los textos. La tarea obvia de tal descripción era dar cuenta de las relaciones de coherencia (semántica) entre oraciones (van Dijk, 1972, 1977) ${ }^{90}$.

A pesar de que las gramáticas de las oraciones también necesitaban explicitar cómo se relacionan semánticamente las cláusulas de oraciones complejas, no había una

${ }^{87}$ N. E.: "From Text Grammar to Critical Discourse Analysis. Academic Autobiography", en Mcs, Discourse Analysis, 18/06/1998. Versión en español: BELIAR (Boletín de Estudios Lingüísticos Argentinos), Vol. 2, $\mathrm{N}^{\circ}$ 6, Buenos Aires, 1995, pp. 20-40.

${ }^{88}$ Es imposible listar siquiera las referencias más importantes de los estudios de los investigadores que más han influido en mi trabajo, o de los que he aprendido mucho durante los últimos 25 años. Gran parte de estas referencias serán las mismas para la mayoría de los lingüistas y analistas del discurso que están al día con la literatura. Obsérvese también que estas influencias fueron más bien temporales, pues me fui interesando por otras disciplinas, campos, tópicos y metodologías. No soy el tipo de académico que tiene Maestros Venerados.

${ }^{89}$ El influjo de la Gramática Generativa sobre mis ideas acerca de la Poética Generativa, y después sobre las Gramáticas del Texto, está primero que todo en deuda con Noam Chomsky, cuyos libros me llevaron más y más hacia la lingüística, y por fuera de la teoría literaria. Debería mencionar todas sus obras de esa época, pero Aspects of the Theory of Syntax (Cambridge, MA: MIT Press, 1965) fue, por supuesto, la más influyente por aquel entonces. Ya que yo estaba más interesado en la semántica, los trabajos de George Lakoff y James McCawley me fueron muy útiles. No podría mencionar un texto en particular, pues a menudo eran artículos mimeografiados y publicados después en diferentes libros.

${ }^{90} \mathrm{Mi}$ trabajo sobre Gramática del Texto fue parcialmente hecho en colaboración con amigos y colegas en Alemania, como Janos Petöfi, Hannes Rieser, Jens Ihwe y, más generalmente, también con Siegfred Schmidt. 
investigación seria en ese tiempo que pudiera extenderse a la semántica lineal del discurso.

Bajo la influencia de la Semántica Estructural francesa (Greimas) ${ }^{91}$ asumí por lo tanto que las relaciones de significado entre oraciones tenían que ser definidas en términos de la identidad de los "lexemas" o "semas" de las palabras en tales oraciones. Más tarde, esta suposición resultó ser totalmente errónea, aunque mantuvo su popularidad en la Semántica Estructuralista francesa por años.

Lo importante es que no son sólo las relaciones de significado entre oraciones las que definen la coherencia, sino más bien las relaciones referenciales, es decir, las relaciones entre las "cosas" que las oraciones denotan en un texto, como veremos más adelante.

Lo nuevo e interesante en esta teoría emergente de la gramática del texto era la introducción de "macroestructuras", una noción desconocida en todas las formas de la gramática de la oración.

Lo fundamental de las macroestructuras era que mostraban cómo los textos no sólo tienen relaciones locales o microestructurales entre oraciones subsecuentes, sino que también tienen estructuras generales que definen su coherencia y organización global.

En mis primeros trabajos, tales macroestructuras eran de dos clases: es decir, estructuras globales de significado y estructuras globales de forma. Más tarde introduje la noción de "superestructura" para referirme a las últimas estructuras, o sea, las estructuras abstractas, esquemáticas, que organizan la forma general del texto, tal como las conocemos desde la teoría de la narrativa o desde la teoría de la argumentación (van Dijk, 1980).

La pregunta -después de más de 25 años- es si estas gramáticas del texto eran erróneas o correctas. Tal como lo veo ahora, diría que los principios básicos de la gramática del texto todavía tienen sentido en la actualidad, como lo demuestra el gran volumen de trabajo que se sigue haciendo en muchos tipos de gramáticas del discurso, en algunos casos muy sofisticadas.

En efecto, así como una gramática de la oración puede explicar por qué secuencias arbitrarias de palabras no definen oraciones, una gramática del texto necesita dar cuenta del hecho de que las secuencias arbitrarias de oraciones no definen un texto. No obstante, la manera como hicimos la gramática del texto era muy primitiva: bastante especulativa, imprecisa, y en parte mal orientada; a pesar de ello, uno de sus logros fue reconocer la importancia de la noción de "coherencia" en toda teoría semántica del

\footnotetext{
${ }^{91}$ Como estudiante de Lengua y Literatura francesa y joven estructuralista en los 60 estuve por supuesto influenciado muchísimo por la semiótica que surgía entonces en Francia, practicada por gente (¡tan diversa!) como Greimas, Barthes, Todorov, Kristeva y otros, a quienes conocí durante mis estudios en París en 1969 y en encuentros posteriores. Durante este período me interesé por los trabajos de A. J. Greimas Semantique Structurale (Larousse, 1966) y Communications 8 (Seuil, 1966) -sobre análisis de la narrativa-, entre muchas otras publicaciones. Por cierto, mi interés por la "Gramática Generativa" causó revuelo en un seminario de Greimas en París cuando hice una presentación allí sobre semántica generativa, Greimas me interrumpió cada cinco minutos, y también dejó muy claro lo que él pensaba de la semántica generativa. Este fue uno de los encontronazos evidentes que conozco entre la Gramática Generativa norteamericana, que por aquel entonces también conquistaba Europa, y la Lingüística Estructuralista francesa, que pronto quedó reducida al fenómeno local francés (y que aún se encuentra entre el trabajo de los semióticos y los investigadores en literatura de todo el mundo).
} 
discurso, y la idea obvia de que los textos también están organizados en niveles más globales, más generales de descripción.

Estudios posteriores, también en psicología, acerca de tal coherencia local (interoracional) y global (textual) resultaron ser más sofisticados. Fue así como en mi libro Text and context (1977) enfaticé que la coherencia local entre oraciones debería estar basada en relaciones referenciales entre "hechos en un mundo posible"; por eso usé entonces la noción popular de "mundo posible" de la semántica formal y la filosofía. Es decir, dos proposiciones subsecuentes P1 y P2 son coherentes si denotan dos hechos F1 y F2 que están (por ejemplo, condicional o causalmente) relacionados.

En mi trabajo posterior con Walter Kintsch sobre la psicología del procesamiento del texto, esta relación referencial no fue definida en términos de hechos "en algún mundo posible", sino en términos de modelos mentales, como se verá más adelante.

Pronto otra dimensión de la coherencia local se puso en evidencia. Las oraciones (o sus significados: proposiciones) no solamente son coherentes debido a las relaciones entre los hechos que denotan, sino también debido a las relaciones entre sus significados mismos. En términos más formales: la coherencia no era sólo "extensional", sino también "intencional" ${ }^{92}$.

Sin embargo, esta relación de significado no estaba definida en términos de los significados de palabras aisladas (como en la semántica estructuralista), sino en términos de relaciones entre proposiciones completas. Por ejemplo, dos proposiciones P1 y P2 pueden también ser coherentes si P2 es una Generalización, una Especificación, una Explicación o un Ejemplo de P1. O sea que estas nociones definen una relación funcional entre proposiciones subsecuentes: P2 tiene la función de ser una Generalización de P1, una Especificación, etc. La investigación posterior, en La teoría de la estructura retórica, de Mann y Thompson, desarrolla más allá este tipo de relaciones funcionales entre las oraciones de textos.

En ese momento, la noción de "macroestructura" se definió específicamente en términos de reglas semánticas bastante precisas para la derivación de macroproposiciones a partir de secuencias de microproposiciones. De este modo, tenemos una explicación formal del fenómeno familiar de "resumir" un texto mediante su información fundamental.

En la psicología del procesamiento del texto, estas macroestructuras jugaron luego un rol fundamental en aclarar la manera como los usuarios del lenguaje entienden, almacenan y recuerdan los textos.

No obstante, es extraño ver que aún hoy existen gramáticas del discurso que sólo operan en un nivel "lineal" de oraciones o proposiciones subsecuentes y que ignoran por completo las estructuras globales principales (macroestructuras, superestructuras) que definen el significado y la forma general de los textos.

\footnotetext{
92 N. E.: "Extensión o Denotata: Propiedad del referente. Interpretación Extensional: El estudio de los referentes que pueden ser denotados por las expresiones de cualquier lengua. Intensión: Llamada también significado, corresponde a las estructuras conceptuales atribuidas a las palabras (morfemas), cláusulas y oraciones. Puede definirse como la propiedad de las expresiones que les permite tener extensión. Interpretación Intencional: La asignación de significados”. Bernal León-Gómez, Jai. Tres momentos estelares de la lingüística. Bogotá: Instituto Caro y Cuervo, 1984, p. 274.
} 
Una razón importante para esta omisión es probablemente el hecho de que las macroestructuras son aún objetos extraños en la teoría gramatical, estructuras que necesitan una explicación diferente a la dada a las estructuras del significado de las oraciones o a las relaciones entre oraciones.

\section{Psicología del procesamiento del texto}

Debido a que mis colegas lingüistas, aun en gramática del texto, no se sintieron muy cómodos con nociones extrañas tales como las "macroestructuras", me volqué a la psicología en busca de inspiración y apoyo ${ }^{93}$, y así conocí a Walter Kintsch.

Este psicólogo americano descendiente de austriacos había escrito un libro, The Representation of Meaning in Memory (Hillsdale: N. Erhbaum, 1974), en el cual se afirmaba explícitamente -por primera vez en la psicología- que el objeto de estudio de una psicología cognitiva del entendimiento no deberían ser las oraciones aisladas, sino los textos completos. A partir de ahí se refería a mi tesis doctoral de 1972 sobre gramática del texto. Un día nos encontramos, y por más de 10 años -mientras yo estaba escribiendo Text and context (1977) y estudios sobre pragmática del discurso (van Dijk, 1981)trabajamos juntos en varios artículos, y finalmente en un libro (van Dijk y Kintsch, 1983).

Muchas de las ideas originales de la gramática del texto, incluyendo las elusivas macroestructuras, lograron encuadrarse dentro de la teoría cognitiva de la comprensión del texto. Sin embargo, mientras al principio los procesos y las representaciones mentales involucrados en el procesamiento estaban demasiado cerca -en cuanto a la forma- de las estructuras y reglas de las gramáticas del texto, más tarde descubrimos que los usuarios del lenguaje "real" son, por supuesto, mucho más flexibles y al mismo tiempo más falibles: cometen errores.

Se creó así la noción de "entendimiento estratégico", para tratar de explicar de la manera más realista qué hacen los usuarios del lenguaje cuando entienden un texto. Por ejemplo, mientras una gramática asigna una estructura a una oración (o secuencias de oraciones) que ya ha sido (abstractamente) "dada", los usuarios del lenguaje comienzan con la interpretación (tentativa) de las primeras palabras de una oración antes de que ésta haya sido escuchada o leída por completo.

Dicho de otro modo, el entendimiento es on line (lineal), y no post hoc (posterior). Tal entendimiento estratégico es muy rápido y efectivo, pero también es hipotético: los errores pueden repararse después.

A diferencia de las gramáticas, los usuarios del lenguaje pueden usar información del texto y del contexto al mismo tiempo u operar simultáneamente en varios niveles del texto (fonológico, sintáctico, semántico, pragmático) para interpretarlo. En resumen, el procesamiento real del texto es muy diferente del análisis formal o estructural del texto.

Además de lo anterior, los usuarios del lenguaje representan oraciones y sus significados en la memoria; es decir, que una teoría psicológica es una teoría de procesamiento

\footnotetext{
${ }^{93}$ Entre los muchos libros e innumerables artículos que leí sobre psicología cognitiva e inteligencia artificial, y sobre procesamiento del texto en particular, debería mencionar la influencia crucial de la obra de Schank y Abelson sobre guiones: Scripts, Plans, Goals and Understanding. An Inquiry into Human Knowledge Structures (Hillsdale: N. Erhbaum, 1977). Durante los años 80 particularicé mi visión sobre la psicología social, y una vez más un libro se destacó como un texto (recomendado) hasta hoy: Fiske, S. T., y Taylor, S. E., Social Cognition (Nueva York: MacGraw-Hill, 1991, 2ª edición). 
mental. Esto significa, por ejemplo, que la Memoria a Corto Plazo puede tener una capacidad limitada y necesita ser vaciada regularmente, después de lo cual su información interpretada es almacenada en la Memoria a Largo Plazo.

Así, para todos los niveles del discurso, Kintsch y yo describimos las estrategias involucradas en su análisis, interpretación y almacenamiento en la memoria. En lugar de condiciones o reglas para la coherencia local o la derivación de macroestructuras, en ese momento teníamos estrategias efectivas para su manipulación en las mentes de los usuarios del lenguaje.

El resultado de tal proceso de entendimiento es una Representación del Texto en la parte episódica de la Memoria a Largo Plazo, o sea, la parte de ella que representa las experiencias personales de la gente. La noción de "macroestructura" jugaba un rol básico en este proceso y representación: era una estructura construida por el usuario del lenguaje para organizar la representación de un texto en la memoria.

En otras palabras, las macroestructuras en una teoría psicológica son subjetivas: explican cómo entienden los usuarios del lenguaje qué es lo más importante en un texto.

Fue necesario introducir otro elemento importante que faltaba en la gramática del texto: el conocimiento. Para entender un texto necesita presuponerse una vasta cantidad de conocimiento sociocultural del "mundo". (Por cierto, a menudo será imposible definir relaciones de coherencia entre oraciones 0 construir macroestructuras sin tal conocimiento).

Para la misma época (1977), Schank y Abelson publicaron su famoso libro acerca de los "guiones", tomados como las formas abstractas en que la gente organiza su conocimiento acerca de los sucesos estereotipados, tales como comprar o comer en un restaurante. En otras palabras, para entender un texto, los usuarios del lenguaje normalmente activan uno o más guiones y usan la información pertinente en la construcción de una Representación del Texto en la Memoria Episódica.

En nuestro trabajo posterior, Kintsch y yo introdujimos otra noción importante: un "modelo" ("situación"), un concepto también usado, aunque de manera diferente, por el psicolingüista Johnson-Laird en su libro Mental Models (1983).

Lo importante de esta noción era que los usuarios del lenguaje no construyen simplemente una representación (semántica) del texto en su Memoria Episódica, sino también una representación del hecho o situación de que trata el texto, por ejemplo un accidente automovilístico.

Esta noción de "modelo" resultó muy exitosa, pues explicaba muchas cosas que hasta ese momento eran oscuras o ignoradas. En primer lugar, daba una base maravillosa a la teoría de la coherencia textual: las oraciones (o sus proposiciones) se definieron simplemente como coherentes en relación con un modelo; en otras palabras, si la gente es capaz de construir un modelo posible y plausible para una secuencia o un texto completo, entonces el texto es (al menos subjetivamente) coherente. De manera semejante, las "macroestructuras" de los textos podían relacionarse con las "macroestructuras" de modelos de nivel superior.

En segundo lugar, los modelos también preveían una elegante explicación para el hecho de que cuando la gente recuerda un texto, a menudo recuerda "falsamente" información 
que nunca fue expresada en el texto original. Sin embargo, si suponemos que la gente durante el entendimiento también construye un modelo de un hecho, y si mucha de la información en tal modelo puede ser derivada desde un conocimiento más general, sociocultural, entonces estos falsos recuerdos pueden ser explicados en términos de los contenidos del modelo construido para un texto.

En otras palabras, lo que la gente recuerda de un texto no es tanto su significado, sino más bien el modelo que construye acerca del hecho sobre el que trata el texto. Esto es por supuesto trivial cuando advertimos que la mayoría de los lectores están interesados no tanto en el significado abstracto de un texto, sino en la información acerca de la "realidad".

En resumen: entender un texto significa que la gente es capaz de construir un modelo mental para él. E inversamente, en la producción del texto, el modelo es el punto de partida para todo procesamiento: la gente sabe algo acerca de un hecho, y este conocimiento está representado en su modelo del hecho; así, este modelo servirá como la base, por ejemplo, para contar una historia acerca del hecho.

Finalmente, los modelos también explican cómo el conocimiento general está relacionado con el procesamiento textual: mientras los modelos son personales, subjetivos y ad hoc (unidos al contexto actual del entendimiento), el conocimiento puede ser visto como una generalización y una abstracción desde tales modelos.

El aprendizaje a través de las experiencias propias es, por lo tanto, una operación sobre modelos. Inversamente, el conocimiento general es usado por fragmentos de "instanciación" de tal conocimiento en modelos específicos. Muchos experimentos posteriores en psicología cognitiva confirmaron que los modelos ciertamente juegan un rol crucial en la comprensión y el recuerdo.

Además de los modelos de los hechos sobre los que se ha hablado o escrito, los usuarios del lenguaje también construyen modelos del hecho comunicativo en el cual participan. Estos así llamados "modelos del contexto" están constituidos por las representaciones subjetivas de sí mismos, de los otros participantes del habla, del entorno (tiempo y espacio), de las relaciones sociales entre los participantes y de sus propósitos y objetivos generales.

Tales modelos del contexto, por lo tanto, también forman la base mental para dar cuenta de los actos de habla dependientes del contexto, del estilo y de la retórica. Dicho de otro modo, estos modelos controlan de qué manera se selecciona la información de los modelos de hechos y, eventualmente, de qué manera se expresa en el discurso.

Mientras en este trabajo cognitivo sobre el discurso el objetivo más importante era el procesamiento individual, y sólo se prestaba una atención limitada a las representaciones generales, abstractas y socialmente compartidas (tales como el conocimiento), mi trabajo posterior sobre ideología (ver más adelante) agregó además la postura de que los modelos ( $y$, por lo tanto, el discurso basado en ellos) contienen también creencias evaluativas, es decir, opiniones sobre los hechos sociales y comunicativos.

Estas opiniones son en parte personales y en parte están basadas en las estructuras de opinión compartidas socialmente: actitudes e ideologías. Gran parte de mi trabajo durante los 80 , incluyendo la investigación sobre prejuicios, se centró en estas "cogniciones sociales" subyacentes al procesamiento del texto. 


\section{Pragmática del discurso}

A diferencia de la mayoría de los investigadores, tengo una concepción más restringida y precisa de la pragmática (formal), entendida como el estudio de los actos de habla y de las secuencias de actos de habla.

Mientras la sintaxis tiene que ver con las formas, y la semántica con los significados o las referencias, la pragmática tiene que ver con la acción. $Y$ mientras que la sintaxis provee reglas de buena formación, y la semántica las condiciones de significación, la pragmática formula las condiciones de propiedad de las emisiones definidas como actos (de habla).

O sea que, para mí, la pragmática no es el estudio del "uso" del lenguaje, ni -como Charles Morris lo había señalado 60 años atrás- el estudio de las relaciones entre los "signos" y sus usuarios. Si éste fuera el caso, la psicolingüística, la sociolingüística, la etnolingüística y el análisis del discurso serían todos parte de la "pragmática". Serían extensiones bastante inútiles al alcance de la pragmática.

Lo mismo es cierto para el estudio de las estrategias interaccionales específicas, tales como las de la cortesía y las del manejo de la impresión dada. Estas son parte de una teoría de la interacción (conversacional) y no, en mi opinión, de una teoría de la pragmática. Pero, como dije, la noción de "pragmática" es usada de manera un tanto general y vaga para denotar estudios sobre la acción, la interacción y las relaciones entre los participantes del habla.

Mis pocos estudios sobre pragmática se centraron en la pragmática del discurso, naturalmente, y no en la pragmática de las oraciones aisladas (van Dijk, 1981).

Sería interesante que la teoría de la coherencia semántica fuera usada como un ejemplo para una teoría de la coherencia pragmática de secuencias de actos de habla: los actos de habla A1 y A2 son coherentes si A1 es una condición posible para el logro apropiado de A2.

Podemos enmarcar las secuencias de los actos de habla dentro de macroactos de habla generales, así como enmarcamos las secuencias de las proposiciones dentro de macroproposiciones.

En otros términos: en su totalidad, un informe de noticias es una afirmación y una nota de rescate es una amenaza global.

Esto puede ser también lo que los usuarios del lenguaje recuerdan de una conversación: no tanto actos de habla locales detallados, sino más bien el soporte o el eje general pragmático de un discurso, es decir, su acto de habla general.

De esta manera, la noción de "macroacto de habla general" fue sistemáticamente relacionada con las macroestructuras semánticas: el "contenido" proposicional de un macroacto de habla generalmente es una macroproposición.

\section{Discurso y racismo}

En 1980 mi trabajo tomó una orientación un tanto diferente. Con motivo de mi primera estadía prolongada en un país del "Tercer Mundo", durante la enseñanza de un curso en el Colegio de México, finalmente decidí que era hora de hacer algo serio. 
Las Gramáticas del Texto y las teorías psicológicas tenían muy poco que ver con los problemas reales de este mundo, y pensé que ya era tiempo de trabajar en problemas con contenidos más sociales y políticos.

Uno de estos problemas fundamentales, especialmente en Europa, era el racismo. Por lo tanto, comencé a interesarme en las formas como se expresa, reproduce y legitima el racismo a través del texto y el habla ${ }^{94}$.

\subsection{Conversaciones}

En varios proyectos extensivos estudié sistemáticamente las diversas maneras como las mayorías blancas piensan, hablan y escriben sobre las minorías étnicas, los inmigrantes, los refugiados y, en general, sobre "la gente del Sur".

Un proyecto mayor, por ejemplo, se centró en cómo los miembros de un grupo mayoritario en Holanda y en California hablan acerca de los otros en las conversaciones de todos los días. Después de grabar, transcribir y analizar cientos de entrevistas espontáneas en varios vecindarios en Amsterdam y San Diego, mis estudiantes y yo encontramos, en todos los niveles de la estructura, que tales conversaciones son bastante típicas (van Dijk, 1984, 1987).

Así, a nivel de los temas, encontramos que, a diferencia de otras conversaciones, sólo un número muy limitado de temas tienden a surgir cuando la gente habla acerca de los "extranjeros". Tales temas generalmente tratan sobre Diferencias Culturales, Desvíos (crimen, violencia, etc.) y Amenazas (económicas, sociales, culturales); por lo tanto, expresan y reproducen estereotipos y prejuicios mayoritarios.

En el nivel local de las relaciones semánticas entre oraciones, encontramos que la gente hace uso de "movimientos" semánticos específicos, tales como los negadores de la Negación Aparente ("Yo no tengo nada contra los Negros, pero...") y de la Concesión Aparente ("No todos los Negros son criminales, pero...").

Estos movimientos parecen implementar localmente las estrategias conversacionales generales de la Autopresentación Positiva ("No somos racistas", "Somos tolerantes", etc.) y de la Presentación Negativa del Otro (la parte negativa que sigue al "pero..."). Se puede inferir que la parte "positiva" consiste en su mayoría en formas de mantener la imagen a partir del hecho de que, de lejos, la mayor parte de las conversaciones son negativas acerca de "ellos".

En un análisis del relato de cuentos encontramos, además, que la categoría narrativa obligatoria de la Resolución está a menudo ausente en las historias sobre inmigrantes.

\footnotetext{
${ }^{94}$ Es difícil señalar aquí las fuentes más importantes e influyentes en mi trabajo sobre discurso y racismo, debido a que prácticamente no hubo investigaciones sobre el tema. La inspiración diaria y la mayor consistencia en la comprensión y el estudio del racismo fueron por supuesto de mi esposa, Philomena Essed, cuyos inspiradores libros Everyday Racism (Claremont, CA: Hunter House, 1990) y especialmente Understanding Everyday Racism (Newbury Park, CA: Sage, 1991)

considero los mejores. Muy pronto Ruth Wodak en Viena entró en este campo, y su estudio sobre antisemitismo en Austria está tan influenciado por mi trabajo como el mío por el de ella, y desde hace muchos años hemos sido no sólo buenos amigos, sino también colegas que se inspiran mutuamente. Ver, por ejemplo, su libro (no traducido aún al inglés o al español) con algunos de sus colegas: Wodak, R., Pelikan, P., Gruber, J., De Cillia, R., y Mitten, R. Wir sind unshuldige Tater. Studien zum antisemitischen Diskurs in Nachkriegsosterreich ("Somos perpetradores inocentes. Estudios sobre el discurso antisemítico de la postguerra en Austria") (Frankfurt/Main: Suhrkamp, 1990).
} 
Esto parece sugerir que en sus modelos mentales de los hechos étnicos, la gente blanca no ve realmente una "solución" para el "problema" de los extranjeros.

De esta manera, las historias se focalizan sobre la Complicación (generalmente negativa), y de hecho se convierten en historias de queja que tienen una función en un argumento, en el cual las experiencias personales de la historia sirven como las premisas creíbles de conclusiones negativas tales como "Ellos no quieren adaptarse" o "Ellos sólo vienen aquí a vivir de nuestro bolsillo", etc.

El estilo, la retórica y otras propiedades formales de estas conversaciones completan esta imagen global. De hecho, los pronombres y demostrativos pueden ser usados selectivamente para resaltar la distancia social, por ejemplo, cuando los hablantes prefieren referirse a sus vecinos Turcos con el pronombre "ellos" o "esa gente" que referirse a ellos, como sería normal, con la frase descriptiva "mis vecinos (Turcos)".

En las conversaciones encontramos también que la gente tiende a titubear, cometer errores o corregir cuando tiene que nombrar a los Otros, una brecha de fluidez que puede ser explicada en términos de mantener (cognitiva y socialmente) los modos y las estrategias del manejo de la impresión dada al hablar en el trabajo sobre un tema "delicado" como el de las minorías.

\subsection{Prensa}

Los otros estudios sobre la expresión del prejuicio étnico y la reproducción del racismo en el discurso giraron en torno al texto y al habla, institucionales y de élite.

Uno de los proyectos mayores se centró en la prensa ${ }^{95}$. Así, analizamos muchos miles de noticias en la prensa inglesa y holandesa (van Dijk, 1991). Lo que queríamos saber, antes que nada, era cómo escriben las principales cadenas de diarios sobre los Otros, y qué rol juega la prensa en las relaciones étnicas, la propagación de los estereotipos y la reproducción de la dominación blanca, es decir, el racismo en general.

Es interesante, aunque no inesperado, que muchos de los rasgos de las conversaciones cotidianas puedan ser observados en la prensa, y en consecuencia podemos suponer que hay relaciones mutuas entre lo que el público en general dice acerca de los "extranjeros" y lo que dicen sus diarios. Por ejemplo, también en la prensa, la selección de tópicos importantes acerca de las minorías es restringida y estereotipada, cuando no negativa.

Encontramos un enfoque especial en la Diferencia, el Desvío y la Amenaza. El crimen étnico, también en la prensa respetable y liberal, es un tema tan importante como lo son los muchos problemas asociados con la inmigración.

Esto significa que el lado positivo de la inmigración (contribuciones a la economía, variación cultural, etc.) rara vez sea tema en la prensa. Las minorías son siempre retratadas como Gente Problemática, mientras que los problemas que "nosotros" les causamos a "ellos", tales como la falta de hospitalidad, las leyes duras de inmigración, la discriminación y el racismo son raramente tópicos importantes.

\footnotetext{
${ }^{95}$ De los muchos libros que leí sobre las noticias, el que más me gustó es el excelente estudio de Gaye Tuchman Making News (Nueva York: Free Press, 1978), y también Processing the News, de Doris Graber (Nueva York: Longman, 1984). Aunque apenas se ocuparon del lenguaje o el discurso, el primero abordó la microsociología y el segundo la psicología cognitiva del «manejo» de noticias.
} 
Los modelos de citas son predecibles de modo similar. Por sus propias reglas de equilibrio, uno esperaría que la prensa citara también a voceros minoritarios competentes y creíbles que hablen acerca de los hechos étnicos.

Sin embargo, nada está más lejos de la verdad: se citan casi exclusivamente las instituciones y las élites (de las mayorías) blancas. Y cuando las minorías son citadas, nunca pueden hablar por sí mismas. Es cuando surgen temas difíciles como la discriminación o el racismo: si a los Otros se les permite hablar acerca de eso, sus opiniones siempre son vistas como una acusación no sustentada (y por lo tanto el "racismo" aparece la mayoría de las veces entre comillas) y no como un hecho.

Estas estructuras tendenciosas, que también pueden ser observadas en el desdecirse, en las descripciones de actores minoritarios, en la estructura de los titulares, en el estilo y en la retórica, pueden ser predecibles cuando nos damos cuenta de que la sala de redactores de la mayoría de los diarios en Europa es aún virtualmente "blanca": muy pocos periodistas de minorías trabajan para grandes diarios, y nunca en los niveles editoriales más altos. Así mismo, se considera a las organizaciones y voceros minoritarios como menos creíbles, menos "objetivos", y, por lo tanto, se les da menos acceso a la prensa.

La conclusión de esta investigación a gran escala fue que aunque en algunos aspectos la prensa apenas refleja lo que los políticos o el público general dice de las minorías, ella también tiene su rol y su responsabilidad en los problemas étnicos. En especial por su inmenso espectro y poder: a diferencia de un hablante tendencioso en una conversación, una noticia o editorial tendencioso puede tener cientos de miles, y-como en el caso de los tabloides británicos- algunas veces millones de lectores, y por lo tanto tener gran influencia. En nuestra investigación sobre las conversaciones cotidianas con frecuencia logramos observar esta influencia de la prensa. Por esto llegamos a la conclusión de que la prensa en Europa juega un rol central en el mantenimiento ( $y$ algunas veces en el agravamiento) del "statu quo étnico", cuando no en la reproducción del racismo.

Estos estudios acerca del rol de la prensa en la reproducción del racismo corren paralelos a otro proyecto en los 80: un estudio sistemático sobre las estructuras, la producción y la recepción de las noticias en la prensa (van Dijk, 1988a, 1988b). Es sorprendente, pero se ha hecho muy poco trabajo analítico del discurso en torno a esta forma particular de discurso escrito, probablemente la que más penetra en nuestra vida cotidiana.

En varios estudios teóricos y empíricos intenté, por lo tanto, extender el análisis del discurso a uno de sus dominios más obvios de aplicación: la investigación de los medios masivos de comunicación.

Supuse que el discurso de las noticias tenía una estructura canónica o "esquema de noticias" que las organiza y enfatiza; así, resulta obvio el hecho de que la producción de noticias también es en gran medida una forma de procesamiento del texto, es decir, de los muchos textos fuente (escritos o hablados) que el periodista usa cuando escribe una noticia.

Uno de los estudios empíricos examinó cómo fue cubierto en el mundo de la prensa un evento (en este caso, el asesinato del presidente electo de Líbano, Bashir Gemayel, en septiembre de 1982). 
De este modo, cientos de historias en un gran número de diarios en muchas lenguas fueron sistemáticamente estudiados para ver si había "universales" de las noticias y/o en dónde las noticias de diferentes países, lenguas, culturas y sistemas políticos proveerían normalmente un "cuadro" diferente del hecho.

Una de las conclusiones de esta investigación fue que las noticias en todo el mundo, posiblemente bajo la influencia del formato de los reportes de las agencias de noticias internacionales, eran bastante semejantes. Existen diferencias más bien entre la prensa de calidad y la prensa popular, el tabloide.

\subsection{Manuales}

Otra fuente importante de estereotipos y prejuicios étnicos, de los cuales cientos de miles de chicos son víctimas, son los libros escolares. Por lo tanto, analizamos un gran número de manuales de ciencias sociales de las escuelas secundarias y les hicimos las mismas preguntas que a los otros proyectos: ¿qué dicen acerca de las minorías? y ¿cuál es el rol que juegan en la reproducción del prejuicio y el racismo?

Aunque en Estados Unidos la situación está mejorando poco a poco con la introducción de más materiales de aprendizaje "multicultural", la mayoría de los libros escolares, sobre todo en Europa, continúa o bien ignorando por completo a las minorías (implicando así que Europa -y las aulas- son aún homogéneamente "blancas"), o bien tendiendo a confirmar estereotipos simples e incluso prejuicios racistas.

Tanto las minorías como la gente del Sur en general están representadas no sólo como "pobres", "atrasados", o "primitivos", sino también como criminales y agresivos; y esto ocurre tanto en los medios como en las conversaciones de todos los días. En especial, se enfoca y problematiza el "desvío" cultural, expresado a menudo en hábitos diferentes, otro lenguaje u otra religión. Al igual que sucede con el discurso de élite y el discurso institucional sobre problemas étnicos, la discriminación y el racismo rara vez se topicalizan, o incluso se niegan.

\subsection{Debates parlamentarios y otros "discursos de élite"}

Otro dominio mayor comprometido en el discurso de los problemas étnicos es la política. Por lo tanto, analizamos debates parlamentarios acerca de la inmigración, las minorías o la "Acción Afirmativa"96 en Holanda, Francia, Alemania, Gran Bretaña y Estados Unidos. Por supuesto que tal discurso público y oficial rara vez es abiertamente racista, con excepción de las afirmaciones de los miembros de partidos de la extrema derecha.

Sin embargo, de un modo más indirecto y sutil, es frecuente encontrar muchos de los rasgos típicos del "habla de los extranjeros" que también se encuentran en los medios y en los textos escolares.

Muchos movimientos estratégicos usados para limitar la inmigración o los derechos de las minorías son especialmente interesantes. Condenar a la víctima es una de las principales estrategias: a las minorías se las condena por su propia posición marginal, su falta de trabajo y vivienda, etc. Se sugiere que lo mejor para ellos es que se queden en su propio

96 N. E.: Esta traducción directa de "affirmative action" refiere a las políticas que incrementan las posibilidades de conseguir un trabajo o un ascenso laboral a las mujeres o a las minorías étnicas. Cf. John R. Searle, “¿Está en crisis la enseñanza superior norteamericana?”, en, Revista Vuelta N²19, México, 1995). 
país para poder salir adelante. Un tanto cínicamente puede agregarse en tal discurso que sería mejor para ellos no ser confrontados con el racismo en los barrios pobres donde tuvieran que vivir. $Y$, por supuesto, la inmigración y los inmigrantes se asociarán principalmente con problemas financieros, de empleo y de vivienda, cuando no con el crimen, las drogas, etc.

\subsection{Discurso corporativo}

Dado su rol en el empleo y en el mercado de trabajo, también se estudió el discurso de los gerentes de las corporaciones, a partir de entrevistas con jefes de personal. Como podía esperarse, los gerentes de las corporaciones, como otras élites blancas, niegan que haya discriminación o racismo en sus empresas. Simultáneamente, se oponen de manera radical a cualquier forma de Acción Afirmativa (a la que ellos llaman "Discriminación Inversa").

Ellos pueden ocuparse del desempleo de las minorías (en Holanda tres o más veces más alto que el desempleo de la mayoría), pero siempre culpan a los Otros: no hablan nuestro lenguaje, tienen una cultura diferente, una educación insuficiente, les falta motivación, etc.

El hecho de que otra investigación muestre que más del $60 \%$ de los empleadores prefiere contratar a un hombre blanco, antes que a mujeres u hombres de minorías, obviamente no es parte de sus explicaciones al desempleo de las minorías.

Este tampoco es el caso en los debates en la política y los medios: si las minorías tienen problemas, de alguna manera siempre serán causados por ellas mismas.

\subsection{Discurso de la élite}

Todas las formas de discursos dominantes, mayoritarios, y en especial los distintos géneros del discurso de la élite -como ya ha sido demostrado por los discursos académicos (entre ellos los manuales contemporáneos de sociología)- evidencian muchas semejanzas.

Además de los estereotipos y prejuicios ideológicos, encontramos estereotipos "textuales" en los modos como se tiende a describir a las minorías y a las relaciones étnicas. La estrategia principal en tal texto y habla, es la de la autopresentación positiva de sí mismo y la presentación negativa del otro: "nuestro" racismo es sistemáticamente negado o al menos mitigado, mientras se focalizan y enfatizan "sus" características negativas.

Si el racismo existe en "nuestra" sociedad, entonces debería buscárselo en los ghettos urbanos, esto es, entre los blancos pobres, y nunca entre las élites de las salas de junta de directores, cursos, salas de redacción o cortes de justicia. Las élites, por lo tanto, se presentan siempre a sí mismas como tolerantes y modernas, mientras culpan a las pobres víctimas sociales.

Precisamente, la política populista se referirá (democráticamente) al resentimiento entre la gente que está en contra de más inmigración. También por su rol en la toma de decisiones, la enseñanza, la investigación, el empleo, la burocracia, la información y la comunicación, las élites y sus ideologías y prácticas étnicas tienen un impacto tremendo sobre la sociedad. 
Aunque quizá rara vez sean muy abiertas y duras, las élites a menudo sólo preformulan lo que pronto será aceptado en la sociedad (blanca) en general. En otras palabras, las élites juegan un rol central en la reproducción del racismo (van Dijk, 1993).

\section{Análisis crítico del discurso}

Los comienzos de la década del 90 requirieron extender esta vasta investigación sobre discurso y racismo al estudio más general del discurso, el poder y la ideología ${ }^{97}$. Así, en un estudio examiné los modos en que el "acceso al discurso (publico)", por ejemplo el de los medios, se distribuye sobre variados grupos de gente. Encontré que el acceso al discurso es un importante recurso social (escaso) para la gente, y que en general las élites pueden también definirse en términos de su acceso preferencial al discurso público, cuando no a su control. Este control puede extenderse a los rasgos del contexto (tiempo, lugar y participantes), así como a diferentes rasgos del texto (tópicos, estilo, etc.).

Contra ese trasfondo, y junto con otros investigadores en análisis del discurso y disciplinas relacionadas, se propuso que el análisis del discurso tuviera también una dimensión "crítica"; es decir, que debería participar activamente con su propio estilo académico tanto en debates sociales, como en la elección de la orientación, los tópicos, los problemas y las cuestiones, y hacer estudios que sirvan a los que más los necesitan, antes que a aquellos que los pueden pagar mejor.

El Análisis Crítico del Discurso, de este modo, está volviéndose un movimiento de investigadores que prestan mayor atención a los problemas sociales que a los paradigmas académicos, y en general estudian las muchas formas de (abuso de) poder en las relaciones de género, étnicas y de clase, tales como el sexismo y el racismo.

Quieren saber cómo actúa el discurso, y cómo expresa, perdona o contribuye a la reproducción de la desigualdad. Al mismo tiempo, estos investigadores escuchan las experiencias y las opiniones de los grupos dominados, y estudian los modos más efectivos de resistencia y disenso.

Así mismo, los investigadores críticos en muchos países han conformado una red internacional, CRITICS (Centro de Investigaciones en Textos, Información y Comunicación en Sociedad), disponible en Internet.

Además, desde 1990 se fundó la revista internacional DISCOURSE AND SOCIETY, como un foro amplio para este estudio sociopolítico, que a su vez es más crítico.

Después de mi trabajo crítico sobre racismo, una de las formas como, pienso, seguí contribuyendo a dar las bases al ACD, fue mediante el estudio de las relaciones entre discurso e ideología (usando, por ejemplo, editoriales del Washington Post y del New York Times como mis fuentes principales).

97 El campo del análisis crítico del discurso, y en especial el estudio de la ideología en el que estoy comprometido ahora, es todavía muy joven para señalar las últimas influencias que perdurarán. Sin embargo, el estudio temprano de Roger Fowler y sus colegas fue una importante fuente de inspiración: Fowler, R., Hodge, B., Foress, G., y Trew, T. Language and control (Londres: Routledge \& Kegan Paul, 1979). Después también los estudios críticos y políticos de (coordinados por) Ruth Wodak (por ejemplo, Language, Power and Ideology, Amsterdam: Benjamins, 1989) y Norman Fairclough (Language and Power, Londres: Longman, 1989) tuvieron influencia en mi trabajo. Existen así mismo muchas otras obras anteriores o posteriores, entre las que deseo destacar a Kramarac, C., Schulz, M., y O’Barr, W. M., ed. Language and Power (Beverly Hills, CA: Sage, 1984). 
El objetivo de este proyecto es, primero, redefinir las ideologías de una manera específica y precisa, por ejemplo, como sistemas básicos de la "cognición social", o sea, como representaciones mentales compartidas socialmente que controlan otras representaciones mentales, tales como las actitudes sociales de grupo (incluyendo los prejuicios) y los modelos mentales.

Se postula que las ideologías tienen un esquema interno fijo, es decir, el mismo esquema de la autorrepresentación de los grupos. Tales ideologías también controlan el discurso y otras prácticas sociales (y viceversa: a menudo se usan el texto y el habla para transmitir ideologías de manera persuasiva).

En segundo lugar, queremos investigar sistemáticamente mediante cuáles estructuras del discurso se manifiestan las opiniones ideológicas en el texto y en el habla, tales como las de naturaleza semántica (tópicos, coherencia) y sintáctica (orden de las palabras), el léxico, los actos de habla, etc.

Finalmente, esta dimensión combinada de discurso y cognición estará incluida en un marco sociopolítico, lo que explica parte de su fundamento, sus funciones, y las formas de las ideologías y los discursos en su contexto social (por ejemplo, relativos a los intereses de los grupos sociales). Completar este complejo proyecto comenzado en 1994 de seguro llevará varios años.

\section{Conclusión}

El itinerario académico esbozado arriba, como toda historia y relato, también necesita una conclusión, si no una moraleja. Después de más de 25 años de hacer análisis del discurso, uno tendría que haber aprendido algo acerca de la disciplina y sus practicantes $^{98}$.

Un punto importante para enfatizar es que a pesar de la variedad de los tópicos que estudié, y de la amplia orientación de mi trabajo como académico, tengo sólo una comprensión muy limitada de lo que sucede hoy en muchos países en el ahora muy vasto campo del análisis del discurso. Hay varios dominios y direcciones de investigación que apenas conozco.

No obstante, como editor de revistas (de TEXT y de DISCOURSE AND SOCIETY) y como editor del Handbook of Discourse Analysis y de una introducción de dos volúmenes (Discourse, A Multidisciplinary Introduction), siempre traté de integrar, unificar y desarrollar los diferentes dominios del estudio del texto y el habla como una nueva interdisciplina de "estudios del discurso".

Otra conclusión importante es que mi trabajo representa sólo una de las orientaciones, métodos, teorías y direcciones de investigación. Emergente del Estructuralismo francés en poética y semiótica, pronto se centró en la lingüística moderna, luego en la psicología cognitiva y después en las ciencias sociales.

\footnotetext{
${ }^{98}$ He hecho una lista muy selectiva de algunas de mis "fuentes de inspiración" a lo largo de los años. La influencia real es más diversa y confusa, ya que tengo muy mala memoria para los detalles de lo que leo: tiendo a integrarlo directamente a mi conocimiento y a las teorías sobre algún tema. He olvidado, en realidad, la mayoría de los libros cruciales, así como autores importantes y amigos personales. Pero podría decirse que incluso un individualista como yo hubiera sido incapaz de hacer todo el trabajo que hice sin los miles de libros y autores que leí durante los últimos 30 años en virtualmente todas las humanidades y las ciencias sociales. A los lectores que quieran detalles sobre las fuentes que usé y a las que me referí, les recomiendo consultar mis publicaciones generales.
} 
Esto no significa, sin embargo -en lo que se refiere al dominio de la investigación, los métodos y el estilo de la escritura-, que las otras formas del análisis del discurso sean menos interesantes para mí. El problema es que incluso después de tantos años uno debe necesariamente restringirse.

Mi objetivo es siempre ser claro, pedagógico, y evitar una escritura esotérica: el criterio crucial debe ser siempre que también nuestros estudiantes, y no solamente los iniciados, puedan leer y entender nuestro trabajo.

Para el pesar de muchos lectores, he evitado quedar atrapado en un problema o paradigma, y siempre he querido cambiar de campo y explorar nuevos problemas y modos de hacer análisis del discurso.

Sólo tengo la esperanza de que más gente en el análisis del discurso quiera ser lo suficientemente "tonta" para dejar su campo actual, en el que se siente como en casa, y comience a explorar campos vecinos. Precisamente en los límites de campos y disciplinas se observan nuevos fenómenos y se desarrollan nuevas teorías.

Como puede resultar obvio del relato anterior, el análisis del discurso es, para mí, esencialmente multidisciplinario, e involucra la lingüística, la poética, la semiótica, la psicología, la sociología, la antropología, la historia y la investigación en comunicación.

Lo que me parece importante, sin embargo, es que precisamente por su naturaleza multifacética esta investigación multidisciplinaria debería ser integrada. Deberíamos diseñar teorías complejas que den cuenta tanto de la dimensión textual como de las dimensiones cognitiva, social, política e histórica del discurso. Por cierto, un problema como el racismo no puede ser completamente entendido a la luz de una sola disciplina, o en términos de teorías simples.

Con la disciplina vista como un todo he aprendido mucho acerca del discurso durante los últimos 25 años. Y, no obstante, al mismo tiempo tengo conciencia de que mucho de lo que sabemos es incompleto y está mal orientado. No temo cometer errores, y lo veo como el problema inevitable de todas las disciplinas nuevas y de las exploraciones originales en territorios vírgenes, si sólo estamos dispuestos a admitir tales errores después, cuando otras investigaciones muestren que nos hemos equivocado y dónde lo hemos hecho.

Comparado con las primitivas Gramáticas del Texto del inicio de los 70 , el trabajo formal contemporáneo sobre estructuras del discurso es mucho más sofisticado. Y comparadas con los modelos cognitivos simplistas sociales e interaccionales de texto y habla de hace 20 años, las nuevas investigaciones sobre procesamiento de los textos, estudios del discurso sociopolítico y análisis conversacional también han avanzado considerablemente.

Diferentes géneros de discurso se han estudiado en muchos dominios sociales: en la política, los medios, la educación, el derecho, etc. Se han ido multiplicando los niveles y las dimensiones, así como las categorías analíticas, de forma tal que el análisis del discurso contemporáneo es incomparablemente más complejo y empíricamente más preciso que hace dos décadas.

No obstante, todavía hay mucho por hacer. Hay aún campos que están subdesarrollados (como es el caso de la ciencia política del discurso). Y, lo más importante, sólo ahora 
hemos comenzado a estudiar el discurso en ese marco mucho más relevante de los problemas sociales serios, tales como el racismo.

En mi opinión, el valor real del análisis del discurso como una disciplina en la sociedad depende de su contribución a la solución de tales problemas.

\section{Publicaciones generales}

\subsection{Principales libros citados}

Communicating Racism. Newbury Park, CA: Sage, 1987.

Elite Discourse and Racismo. Newbury Park, CA: Sage, 1993 [Sage Series en "Race and Ethnic Relations", Vol. 6].

Macrostructures. Hillsdale, N.J.: Erlbaum, 1980.

News as Discourse. Hillsdale, N.J.: Erlbaum, 1988a.

News Analysis. Hillsdale, N.J.: Erlbaum, 1988b.

Prejudice in Discourse. Amsterdam: Benjamins, 1983.

Racism and the Press. Londres: Rotledge, 1991.

Some Aspects of Text Grammars. La Haya: Mouton, 1972.

Strategies of Discourse Comprehension (con Walter Kintsch). Nueva York: Academic Press, 1983.

Studies in the Pragmatics of Discourse. La Haya: Mouton, 1981.

Text and Context. Londres: Longman, 1977.

\subsection{Otros libros}

Discourse and Communication, ed. Berlin: de Gruyter, 1985.

Discourse and Discrimination (con Geneva Smitherman), ed. Detroit: Wayne State University Press, 1988.

Discourse Studies, ed. London: Sage, 2 vols., 1997,

- Discourse as Structure and Process, Discourse Studies: A Multidisciplinary Introduction. Vol. 1, 1997.

- Discourse as Social Interaction, Discourse Studies: A Multidisciplinary Introduction. Vol. 2, 1997.

Handbook of Discourse Analysis, ed. Londres: Academic Press, 4 vols., 1985 
Ideology, A Multidisciplinary Approach. London: Sage, 1998.

\subsection{Libros traducidos al español}

Estructuras y funciones del discurso. México: Siglo XXI, 1980 [7ª edición, 1991].

Estudios del discurso, ed. Barcelona: Paidós, 2 vols., 1999.

Ideología. Barcelona/Buenos Aires: Gedisa, 1999.

La ciencia del texto. Barcelona/Buenos Aires: Paidós, 1983.

La noticia como discurso, Comprensión, estructura y producción de la información. Barcelona: Paidós, 1990.

Prensa, racismo y poder. México: Universidad Iberoamericana, 1995.

Racismo y análisis crítico de los medios. Barcelona: Paidós, 1997.

Texto y contexto. Madrid: Cátedra, 1980.

\subsection{Artículos en libros y revistas}

(En orden de publicación en español)

"Aspectos de una teoría generativa del texto poético", en Greimas, A. J. y otros, Ensayos de semiótica poética. Barcelona: Planeta, 1976 [pp. 239-271].

"Gramáticas de texto y estructuras narrativas", en Chabrol, C. Semiótica narrativa y textual. Barcelona: Planeta, 1976.

“El procesamiento cognoscitivo del discurso literario”, en Acta poética, 2, 1980 [pp. 4-26].

"Algunas notas sobre la ideología y la teoría del discurso", en Semiosis, 5. Jalapa, México, 1980 [pp. 37-54].

"Estructuras textuales de las noticias de la prensa", en Analisi, 7/8, 1983 [pp. 77-105].

"La pragmática de la comunicación literaria", en Mayoral, J. A., ed. Pragmática de la comunicación literaria. Madrid: Arco, 1987 [pp. 170-194].

"El discurso y la reproducción del racismo", en Lenguaje en Contexto, 1, 1988 [pp. 131180].

"Nuevos desarrollos en el análisis del discurso, 1978-1988", en van Dijk, Teun A., Estructuras y funciones del discurso. México: Siglo XXI, [1980], $7^{a}$ edición, 1991 [pp. 147185].

“Discurso y desigualdad", en Estudios de periodismo, 1, 1992 [pp. 5-22].

“El racismo de la élite”, en Archipiélago, 14, 1993 [pp. 106-111]. 
"Modelos en la memoria. El papel de las representaciones de situación en el procesamiento del discurso", en Revista Latina de pensamiento y lenguaje, Vol. $2 \mathrm{~N}^{\circ} 1$, México, 1993-1994 [pp. 39-56].

"Élites, prensa y racismo", en van Dijk, Teun A., Prensa, racismo y poder. México: Universidad Iberoamericana, 1995a [pp. 5-44].

"Prensa y poder", en van Dijk, Teun A., Prensa, racismo y poder, México: Universidad Iberoamericana, 1995b [pp. 45-95].

"De la gramática del texto al análisis crítico del discurso", en Beliar (Boletín de Estudios Lingüísticos Argentinos), Vol. 2, N 6, Buenos Aires, 1995c [pp. 20-40].

“Análisis ideológico del discurso", en Voces y Cultura, 10, Barcelona, 1996b [pp. 9-50].

\section{Apéndice: ACD}

\section{1. ¿Qué es el análisis crítico del discurso?*}

El Análisis Crítico del Discurso [ACD] se ha ido convirtiendo en la denominación genérica que se aplica a un planteamiento especial dedicado a estudiar los textos y el habla, y que emerge de la crítica lingüística, la crítica semiótica y, en general, del modo sociopolítico consciente y oposicionista en que se investigan el lenguaje, el discurso y la comunicación.

Sin embargo, al igual que en muchos otros sectores, planteamientos y subdisciplinas que estudian el lenguaje y el discurso, no es fácil delimitar con precisión los principios, prácticas, teorías y métodos especiales del ACD. La labor del ACD se caracteriza normalmente por la utilización de los siguientes criterios.

1. Se dirige más hacia los problemas o los temas que hacia los paradigmas. Cualquier planteamiento teórico o metodológico es adecuado siempre y cuando permita estudiar eficazmente los problemas sociales relevantes, como pueden ser el sexismo, el racismo, el colonialismo u otras formas de desigualdad social.

2. El ACD no conforma una escuela, ni un campo ni una disciplina de análisis del discurso; se trata de un planteamiento, posicionamiento o postura explícitamente críticos para estudiar el texto y el habla.

3. A fin de estudiar eficazmente los problemas sociales o los temas relevantes, el trabajo del ACD suele ser inter o multidisciplinario, y se fija particularmente en la relación existente entre discurso y sociedad (con la inclusión de conocimiento social, política y cultura).

4. Tanto histórica como sistemáticamente, el ACD forma parte de un amplio espectro de estudios críticos (a menudo marginales o marginalizados) sobre humanidades y ciencias sociales, por ejemplo, sociología, psicología, investigación de la comunicación de masas, leyes, literatura o ciencias políticas.

\footnotetext{
" «"Aims of Critical Discourse Analysis”, en Japanese Discourse, Vol. 1, № 1, 1995. 
5. Los estudios efectuados por el ACD pueden (a veces) fijarse en todos los niveles $y$ dimensiones del discurso, es decir, gramaticales (fonología, sintaxis, semántica), estilo, retórica, organización esquemática, actos de habla, estrategias pragmáticas y de interacción, entre otros.

6. No obstante, muchos de los estudios en ACD no se limitan a estos planteamientos de discurso puramente "verbales", sino que también se fijan en otras dimensiones semióticas (imágenes, películas, sonido, música, gestos, etc.) de los sucesos comunicativos.

7. Cuando se estudia el rol del discurso en la sociedad, el ACD se centra particularmente en las relaciones (de grupo) de poder, dominación y desigualdad, así como en la manera en que los integrantes de un grupo social los reproducen o les oponen resistencia a través del texto y del habla.

8. La labor del ACD se dirige, en gran parte, a las estructuras y estrategias de dominio y resistencia, tanto las desarrolladas en el discurso como las legitimadas, y que se hallan en las relaciones sociales de clase, de género, étnicas, raciales, de orientación sexual, lengua, religión, edad, nacionalidad o de nacionalismos.

9. Una gran parte de la labor del ACD se dirige a subrayar las ideologías que desempeñan un papel en la reproducción de o la resistencia a la dominación o la desigualdad.

10. En los objetivos descriptivos, explicativos y prácticos de los estudios del ACD radica un esfuerzo para descubrir, revelar o divulgar aquello que es implícito, que está escondido o que por algún motivo no es inmediatamente obvio en las relaciones de dominación discursiva 0 de sus ideologías subyacentes. EI ACD se centra específicamente en las estrategias de manipulación, legitimación, creación de consenso y otros mecanismos discursivos que influyen en el pensamiento (e indirectamente en las acciones) en beneficio de los más poderosos.

11. El esfuerzo por descubrir los medios discursivos de control mental y de influencia social conlleva la adopción de una postura crítica y de oposición contra los que ocupan el poder y las élites, particularmente contra aquellos que abusan de su poder.

12. Los estudios del ACD, por otra parte, se esfuerzan en formular o mantener una perspectiva global de solidaridad para con los grupos dominados, por ejemplo, formulando propuestas estratégicas que ejerzan y desarrollen un contrapoder y una contraideología cuando se dé la práctica de la confrontación y de la resistencia.

Se da por descontado que no todos los estudios del ACD se caracterizan por la inclusión de la totalidad de estos criterios, ya que no todos se limitan a enumerar estudios críticos, sino que son también parcialmente programáticos, que es a lo que idealmente deberían aspirar los estudios ACD; no obstante, estos criterios aportan la mayoría de los rasgos de un planteamiento que se distingue con bastante claridad del resto de los estudios sobre el discurso.

El ACD se caracteriza esencialmente por ser un estudio oposicional de las estructuras y estrategias del discurso de élite y de sus condiciones y consecuencias cognitivas y sociales, en el que se incluye el discurso de resistencia a dicha dominación. En este 
sentido se puede decir que va más allá de de los criterios metodológicos tradicionales de adecuación observacional descriptiva y explicativa.

Al añadir el criterio de adecuación crítica se presupone la existencia de unas normas y valores sociales y se introduce una ética social o política (lo que consideramos erróneo o correcto) dentro del trabajo académico como tal. No es de extrañar que los estudiosos consideren a menudo "político" (tendencioso) y por lo tanto "no científico" este tipo de planteamiento, puesto que creen que su tarea "objetiva" y carente de crítica no conlleva un compromiso, y por eso está desprovista de su posicionamiento sociopolítico; en efecto, se trata de una actitud conservadora que alimenta el statu quo.

El análisis crítico del discurso hace por lo tanto hincapié en el hecho de que la tarea académica forma parte integrante de la vida social y política, y en consecuencia las teorías, métodos, temas y selección de datos de un estudio del discurso son siempre políticos. Al contrario de otros estudios del discurso implícitamente político, el ACD formula explícitamente su posicionamiento (opositivo).

\section{ACD: una síntesis}

El análisis crítico del discurso es un enfoque especial en el análisis del discurso que se fija en las condiciones discursivas, en los componentes y en las consecuencias del abuso de poder ejercido por grupos élite dominantes e instituciones.

Así mismo, examina los patrones de acceso y control sobre contextos, géneros, texto y habla y sus propiedades, así como las estrategias discursivas de control mental, y estudia el discurso y sus funciones en la sociedad y cómo ésta expresa, representa, legitima o reproduce en texto y habla formas de desigualdad en particular.

EI ACD lleva a cabo esta tarea en oposición a aquellos grupos e instituciones que abusan de su poder y en solidaridad con los grupos dominados, por ejemplo, descubriendo y denunciando la dominación discursiva y cooperando en el incremento del poder del dominado. Unas tareas y objetivos tan altos pueden efectivamente realizarse porque ACD es una empresa teórica y descriptiva seriamente dedicada a eludir la vaguedad del impresionismo y la superficialidad.

ACD significa, por lo tanto, la necesidad de elaborar teorías detalladas de las estructuras y estrategias de texto y habla; en particular, teorías explícitas sobre los roles y las funciones de dichas propiedades dentro del contexto social y el proceso cognitivo. Mientras no existan tales premisas, el ACD será simplemente un programa y no una práctica social y académicamente adecuada.

Por otra parte, el ACD posee sus propios objetivos, programas de investigación, parámetros teóricos y métodos, y puede centrarse en aquellas propiedades del lenguaje y del discurso que otros descartan, como se ha demostrado en los estudios feministas; así mismo, puede subrayar la relevancia del poder y de la dominación en sus estudios de texto y habla, o de los acuerdos sociales y del orden social en su relación con el uso del lenguaje y de la comunicación.

Es apenas necesario subrayar que un programa tan complejo y ambicioso como éste se encuentra todavía en sus inicios. La mayor parte de la tarea del ACD está todavía por llegar. 